Care: Jurnal Ilmiah Ilmu Kesehatan Vol .8, No.2, 2020, hal 235-245

Tersedia online di https://jurnal.unitri.ac.id/index.php/care

ISSN 2527-8487 (online)

ISSN 2089-4503 (cetak)

\title{
GAMBARAN DERAJAT KEPARAHAN GEJALA PASIEN RINOSINUSITIS KRONIK DI RSUD DR. SOETOMO SURABAYA
}

\author{
Anggita Putri Samara'), Budi Sutikno ${ }^{2)}$, Reny I'tishom ${ }^{3)}$ \\ ${ }^{1,2,3)}$ Fakultas Kedokteran Universitas Airlangga \\ E-mail: anggitaputrisamara@gmail.com
}

\begin{abstract}
Chronic rbinosinusitis (CRS) is a sinus paranasal and nasal inflammation marked with two or more symptoms, nasal congestion or nasal discharge and the other symptom like facial pain and reduced smell may present. This symptom occur $>12$ weeks. One of the parameter for symptom's severity assessmentis using Visual Analog Scale (VAS) that can be classified as mild (0-3), moderate (4-7), dan severe (8-10). This study was a observational study by assessing patient's medical record at SMF THT-KL RSUD Dr. Soetomo and analyzed descriptively. 43 patients were enrolled to study (28 male and 15 female), most of them were between age 36-45 years old (25,58\%). Most of the patient's symptom's severity in general, nasal obstruction, nasal discharge, facial pain, and reduced smell were moderate $(65,11 \%)$, moderate $(58,13 \%)$, mild $(41,86 \%)$, mild $(58,13 \%)$, mild (62,79\%) respectively. Most of the patients had risk factor (62,79\%), and the most of the patient's risk factor were allergy. Most of the CRS patients in this study were male, 36-45 years old, with the general symptom's severity moderate, moderate nasal obstruction, mild nasal discharge, mild facial pain, mild reduced smell, and had allergy.
\end{abstract}

Keywords: Chronic rbinosinusitis; risk factor; visual analog scale.

\begin{abstract}
ABSTRAK
Rinosinusitis kronik (RSK) adalah suatu inflamasi hidung dan sinus paranasal ditandai dengan dua gejala atau lebih, salah satunya harus berupa sumbatan atau obstruksi atau nasal discharge (sekret hidung anterior / posterior) dan dapat disertai nyeri pada wajah dan/atau berkurangnya sensitivitas pembau dan berlangsung selama $>12$ minggu. Salah satu parameter untuk mengukur derajat keparahan gejala adalah dengan menggunaka skala Visual Analog Scale (VAS). Skala VAS memiliki klasifikasi derajat ringan (0-3), sedang (4-7), dan berat (8-10). Penelitian ini menggunakan metode observasional deskriptif dengan
\end{abstract}

Cara mengutip: Samara, A. Putri., Sutikno, Budi., \& I'tishom, Reny . (2020). Gambaran Derajat Keparahan Gejala Pasien Rinosinusitis Kronik di RSUD DR. Soetomo Surabaya. Care:Jurnal Ilmiah Ilmu Kesehatan, 8(2), 235-245

Retrieved from https://jurnal.unitri.ac.id/index.php/care/article/view/1666 
menganalisis rekam medik pasien di SMF THT-KL RSUD Dr. Soetomo dengan teknik pengumpulan data total sampling. Penelitian ini mendapatkan 43 pasien (28 laki-laki dan 15 perempuan), paling banyak berumur 36-45 tahun (25,58\%). Kebanyakan derajat keparahan gejala keseluruhan, obstruksi hidung, nasal discharge, nyeri wajah, dan gangguan penghidu adalah sedang $(65,11 \%)$, sedang $(58,13 \%)$, sedang $(41,86 \%)$, sedang $(58,13 \%)$, sedang $(62,79 \%)$ secara berturut-turut. Pasien RSK paling banyak memiliki faktor risiko $(62,79 \%)$, dengan faktor risiko paling sering adalah alergi. Pasien RSK pada penelitian ini paling banyak adalah laki-laki, berusia 36-45 tahun, dengan derajat keparahan gejala keseluruhan dengan skala VAS gejala sedang, gejala obstruksi hidung skala sedang, gejala nasal discharge skala ringan, gejala nyeri wajah skala ringan, gejala gangguan penghidu skala ringan, memiliki faktor risiko alergi.

Kata Kunci : Gejala; rinosinusitis kronik; visual analog scale.

\section{PENDAHULUAN}

Rinosinusitis kronik (RSK) menurut European Position Paper on Rbinosinusitis and Nasal Polyps (EPOS) 2012 adalah inflamasi hidung dan sinus paranasal ditandai dengan dua gejala atau lebih, diantaranya adalah obstruksi hidung atau nasal discharge, dapat disertai nyeri pada wajah dan gangguan sensitivitas pembau selama 12 minggu. (Fokkens, 2012). Meskipun RSK banyak diderita oleh masyarakat, namun data penunjang untuk RSK di Indonesia sangat terbatas. Data mengenai prevalensi RSK di Indonesia mayoritas berasal dari \pm 10 tahun lalu dan tidak bersumber dari DEPKES RI. Penanganan RSK sangatlah bergantung pada diagnosis dari anamnesis pasien. Di Amerika Serikat, prevalensi RSK pada dewasa mencapai 13-16\% dari populasi penduduk (Fokkens, 2012). Sedangkan di Indonesia, prevalensi RSK pada tahun
2004 dilaporkan sekitar 30 juta penduduk (US Census Bureau, 2004). Berdasarkan data DEPKES RI tahun 2003 menyatakan bahwa penyakit hidung dan sinus berada pada urutan ke-25 dari 50 pola penyakit peringkat utama. Data Divisi Rinologi Departemen THT RSCM, jumlah pasien rinologi bulan Januari sampai Agustus 2005 sekitar 435 pasien. Sebanyak 69\% pasien termasuk penderita rinosinusitis, sebanyak $30 \%$ pasien rinosinusitis tersebut memiliki indikasi untuk operasi bedah sinus endoskopik fungsional (DEPKES RI, 2003). Di Surabaya, tepatnya di poliklinik THT-KL RSUD Dr. Soetomo Surabaya tahun 2009, terdapat 916 penderita penyakit sinusitis paranasal (Arimulyani, 2009). Di Amerika, prevalensi gejala pasien RSK adalah obstruksi nasal sebesar 92\%, postnasal drip sebesar $87 \%$ dan infeksi saluran napas sebesar 68\% (Damm, 
2002). Penelitian lain menyatakan, berdasarkan kriteria diagnosis RSTF (Rhino Sinusitis Task Force), prevalensi obstruksi nasal sebesar 84\%, sekret hidung sebesar $82 \%$, dan nyeri wajah sebesar $79 \%$ sebagai gejala yang sering dialami (Ling, 2007). Persentase tidak mencapai total 100\% menggambarkan pasien RSK mengalami banyak gejala, sehingga data merupakan himpunan gejala yang dialami, atau dapat disebut union. Di Amerika, penanganan penderita RSK menghabiskan dana kesehatan sebesar 3,4 milyar dolar per tahun (AAOHNS,2014). Pada tahun 2013 di Kanada, angka prevalensi RSK sekitar $5 \%$ dengan rasio wanita berbanding pria yaitu $6: 4$ (lebih tinggi pada wanita) (Fokkens, 2012).

Rinosinusitis kronik memberi dampak pada kehidupan masyarakat dari berbagai aspek, antara lain aspek kualitas hidup (Quality of Life) dan aspek sosioekonomi (Lund, 2007). Beberapa komplikasi seperti infeksi intrakranial, infeksi orbita, dan mukokel (kista) dapat terjadi pada pasien RSK yang tidak mendapat penanganan baik (Gianonni et al., 2006). Menurut European Position Paper on Rhinosinusitis and Nasal Polyps (EPOS) 2012, beberapa instrumen digunakan untuk menegakkan diagnosis dan mengetahui derajat keparahan gejala yang dialami pasien RSK. Pasien dewasa menggunakan instrumen Visual Analogue Scale (VAS), Sino Nasal Outcome Test-22 (SNOT-22), dan Rbinosinusitis Outcome Measure (RSOM-31). Pasien anak menggunakan instrumen Sinus and Nasal Quality of Life Survey (SN-5). Poli Telingga Hidung Tenggorok Bedah Kepala dan Leher THT-KL RSUD Dr. Soetomo menggunakan instrumen Visual Analogue Scale (VAS) yang mulai diaplikasikan pada Februari 2018.

Penegakan diagnosis dengan merincikan derajat keparahan gejala dapat meningkatkan efektifitas pemilihan terapi (EPOS, 2012). Derajat keparahan gejala RSK diukur dengan VAS dibagi menjadi tiga, yaitu: gejala ringan (skala 0-3), gejala sedang (skala 4-7), dan gejala berat (skala 8-10). Instrumen VAS tidak hanya untuk mengukur derajat keparahan tiap gejala yang dialami (obstruksi hidung, nasal discharge, nyeri wajah, dan gangguan sensitivitas pembau) namun juga digunakan untuk mengukur derajat keparahan keseluruhan gejala. Pada penelitian Lim (2007), pasien rinosinusitis dengan derajat VAS dengan nilai diatas 5 mengaku gejala yang dialami mempengaruhi Quality of Life (QoL) pasien. Beberapa hal mempengaruhi 
derajat keparahan gejala pada pasien RSK, salah satunya adalah faktor risiko. Menurut EPOS 2012, faktor risiko pada pasien RSK yang kemudian diimpelementasikan pada rekam medik poli THT-KL RSUD Dr. Soetomo yaitu alergi, asma, refluks, dan rokok.

Sampai saat ini belum ada penelitian mengenai gambaran derajat keparahan gejala RSK berdasar indikator VAS di RSUD Dr. Soetomo yang baru diaplikasikan mulai bulan Februari 2018. Oleh karena itu, peneliti ingin melakukan penelitian untuk mendapatkan gambaran derajat keparahan gejala RSK berdasar indikator VAS di RSUD Dr. Soetomo.

\section{METODE PENELITIAN}

Penelitian ini observasional deskriptif dengan rancangan retrospektif. Populasi yang diteliti adalah rekam medik pasien RSK di SMF THT-KL RSUD Dr. Soetomo pada bulan Maret 2018 sampai dengan Februari 2019. Untuk mendapatkan populasi terjangkau yang akan dijadikan sampel penelitian dipilih melalui kriteria inklusi dan eksklusi. Sampel yang digunakan dalam penelitian ini adalah rekam medik pasien yang masuk dalam populasi terjangkau. Besar sampel dihitung setelah peneliti menghitung jumlah populasi terjangkau yang memenuhi kriteria inklusi dan eksklusi. Metode pengambilan sampel menggunakan total sampling. Kriteria inklusi sampel adalah pasien dengan umur $\geq 18$ tahun dan merupakan pasien RSK di Poli THT-KL RSUD Dr. Soetomo. Sedangkan kriteria ekslusi sampel adalah rekam medis tidak lengkap (tidak ada nilai VAS umum dan spesifik tiap gejala). Variabel penelitian meliputi variabel bebas dan variabel terikat. Variabel bebas meliputi gejala RSK yaitu obstruksi hidung, nasal discharge, nyeri wajah, gangguan pembauan, faktor risiko (alergi, asma, refluks, rokok), usia, jenis kelamin. Sedangkan variabel terikat meliputi skala indikator Visual Analogue Scale (VAS) 0-3 merupakan gejala ringan, 4-7 merupakan gejala sedang, dan 8-10 merupakan gejala berat. Proses pengambilan data pertama melalui mendapatkan surat perizinan untuk dapat mengakses rekam medik, khususnya di SMF THT-KL RSUD Dr. Soetomo kemudian melakukan identifikasi rekam medik yang sesuai dengan kriteria. Analisis data melalui analisis deskriptif yang bertujuan untuk menjelaskan atau mendeskripsikan karakteristik setiap variabel penelitian. Dalam analisis ini menghasilkan distribusi frekuensi dan persentase tiap variabel, nilai maksimal dan minimal, serta standar deviasi. Penelitian ini telah mendapatkan sertifikat 
Care: Jurnal Ilmiah Ilmu Kesehatan Vol .8, No.2, 2020, hal 235-245

kelaikan etik dari unit Bioetik RSUD Dr.

Soetomo dengan nomor

0838/KEPK/XII/2018.

\section{HASIL}

Angka kejadian RSK pada penelitian ini paling banyak pada rentang usia $36-45$ tahun, dengan persentase sebesar 25,58\% (Tabel 1). Rata-rata usia pasien adalah 41,62 tahun (SD $\pm 16,367)$. Usia termuda pada penelitian ini adalah 18 tahun, sedangan usia tertua pada penelitian ini adalah 73 tahun.

Tabel 1. Distribusi frekuensi usia pasien

\begin{tabular}{ccc}
\hline Usia (tahun) & $\mathbf{f}$ & $\mathbf{( \% )}$ \\
\hline $18-25$ & 10 & 23,25 \\
\hline $26-35$ & 5 & 11,62 \\
\hline $36-45$ & 11 & 25,58 \\
\hline $46-55$ & 7 & 16,27 \\
\hline $56-65$ & 7 & 16,27 \\
\hline$>65$ & 3 & 6,97 \\
\hline Total & 43 & 100 \\
\hline
\end{tabular}

Tabel 2. Distribusi frekuensi jenis kelamin pasien

\begin{tabular}{ccc}
\hline Jenis kelamin & $\mathbf{f}$ & $\mathbf{( \% )}$ \\
\hline Laki-laki & 28 & 65,11 \\
\hline Perempuan & 15 & 34,88 \\
\hline Total & 43 & 100 \\
\hline
\end{tabular}

Berdasarkan data jenis kelamin pasien RSK pada penelitian ini (Tabel 2) jenis kelamin pasien paling banyak adalah lakilaki sebanyak 28 orang $(65,11 \%)$. Perbandingan jenis kelamin pasien RSK laki-laki dan perempuan pada penelitian ini adalah $1,8: 1$.
Tabel 3. Distribusi frekuensi derajat VAS gejala keseluruhan

\begin{tabular}{ccc}
\hline Derajat & f & $\mathbf{( \% )}$ \\
\hline Ringan $(0-3)$ & 4 & 9,31 \\
\hline Sedang $(4-7)$ & 28 & 65,11 \\
\hline Berat $(8-10)$ & 11 & 25,58 \\
\hline Total & 43 & 100 \\
\hline
\end{tabular}

Berdasarkan Tabel 3, derajat VAS keseluruhan terbanyak adalah gejala sedang (65,11\%). Rata-rata VAS keseluruhan adalah 6,04 (SD $\pm 1,904)$. VAS keseluruhan terkecil bernilai 3, dan VAS keseluruhan terbesar adalah 10 .

Tabel 4. Distribusi derajat VAS tiap gejala

\begin{tabular}{|c|c|c|c|}
\hline Gejala & Derajat & $f$ & $(\%)$ \\
\hline \multirow{4}{*}{$\begin{array}{l}\text { Obsruksi } \\
\text { hidung }\end{array}$} & Ringan (0-3) & 8 & 18,60 \\
\hline & Sedang (4-7) & 25 & 58,13 \\
\hline & Berat (8-10) & 10 & 23,25 \\
\hline & Total & 43 & 100 \\
\hline \multirow{4}{*}{$\begin{array}{c}\text { Nasal } \\
\text { discharge }\end{array}$} & Ringan $(0-3)$ & 18 & 41,86 \\
\hline & Sedang (4-7) & 17 & 39,53 \\
\hline & Berat (8-10) & 8 & 18,60 \\
\hline & Total & 43 & 100 \\
\hline \multirow{4}{*}{$\begin{array}{l}\text { Nyeri } \\
\text { wajah }\end{array}$} & Ringan (0-3) & 25 & 58,13 \\
\hline & Sedang (4-7) & 12 & 27,90 \\
\hline & Berat (8-10) & 6 & 13,95 \\
\hline & Total & 43 & 100 \\
\hline \multirow{4}{*}{$\begin{array}{l}\text { Gangguan } \\
\text { penghidu }\end{array}$} & Ringan $(0-3)$ & 27 & 62,79 \\
\hline & Sedang (4-7) & 11 & 25,58 \\
\hline & Berat (8-10) & 5 & 11,62 \\
\hline & Total & 43 & 100 \\
\hline
\end{tabular}

Berdasarkan Tabel 4, derajat VAS obstruksi hidung terbanyak adalah gejala sedang (58,13\%). Rata- rata VAS obstruksi hidung adalah 5,65 (SD $\pm 2,191)$. VAS obstruksi hidung terkecil bernilai 2, dan VAS obstruksi hidung terbesar 
adalah 10. Derajat VAS nasal discharge terbanyak adalah gejala ringan $(41,86 \%)$. Rata-rata VAS nasal discharge adalah 4,604 (SD $\pm 2,258)$. VAS nasal discharge terkecil bernilai 1, dan VAS nasal discharge terbesar adalah 9. Derajat VAS nyeri wajah terbanyak adalah gejala ringan $(58,13 \%)$. Rata-rata VAS nyeri wajah adalah 3,32 $(\mathrm{SD} \pm 3,293)$. VAS nyeri wajah terkecil bernilai 0 (nol), dan VAS nyeri wajah terbesar adalah 10. Derajat VAS gangguan penghidu terbanyak adalah gejala ringan (62,79\%). Rata-rata VAS gangguan penghidu adalah 2,86 (SD $\pm 3,166)$. VAS gangguan penghidu terkecil bernilai 0 (nol), dan VAS gangguan penghidu terbesar adalah 9 .

Tabel 5. Distribusi faktor risiko

\begin{tabular}{lcc}
\hline \multicolumn{1}{c}{ Faktor risiko } & f & $\mathbf{( \% )}$ \\
\hline Alergi & 8 & 29,62 \\
\hline Asma & 0 & 0 \\
\hline Refluks & 2 & 7,4 \\
\hline Rokok & 7 & 25,92 \\
\hline Alergi dan asma & 1 & 3,7 \\
\hline Alergi dan refluks & 4 & 14,81 \\
\hline $\begin{array}{l}\text { Alergi, refluks, dan } \\
\text { rokok }\end{array}$ & 2 & 7,4 \\
\hline Asma dan refluks & 1 & 3,7 \\
\hline $\begin{array}{l}\text { Asma, refluks, dan } \\
\text { rokok }\end{array}$ & 2 & 7,4 \\
\hline \multicolumn{1}{c}{ Total } & 27 & 100 \\
\hline \multicolumn{1}{c}{}
\end{tabular}

Berdasarkan Tabel 5, pasien RSK paling banyak memiliki faktor risiko sebanyak 27 pasien $(62,79 \%)$. Faktor risiko terbanyak adalah alergi sebanyak 15 pasien terdiri dari: 8 pasien dengan faktor risiko alergi saja, 1 pasien kombinasi alergi dan asma, 4 pasien kombinasi alergi dan refluks, 2 pasien kombinasi alergi, refluks, dan rokok.

\section{PEMBAHASAN}

Menurut data dalam penelitian ini, pada Tabel 1, paling banyak adalah rentang usia 36-45 tahun dengan persentase sebesar 25,58\%. Hasil penelitian ini tidak jauh berbeda dari penelitian Riana, dkk., (2016) di Bandung didominasi oleh usia 32-42 tahun sebanyak 38\%. Di Makassar, usia terbanyak penderita RSK adalah rentang usia 30-39 tahun (Rahmawati, 2008). Pada Fokkens (2012), penderita RSK didominasi oleh umur 35-45 tahun dan prevalensinya akan terus meningkat hingga usia 50 tahun. Menurut Cho (2012), salah satu faktor yang mempengaruhi patofisiologi RSK yaitu disfungsi barier epitel akan meningkat seiring usia, namun faktor inflamasi eosinofil akan menurun seiring usia mulai sekitar 60 tahun. Mahdavinia (2013) mengatakan belum ada penjelasan patofisiologi RSK khusus pada kelompok usia tertentu. Beberapa gen dapat berekspresi berlebihan (overexpressed) atau justru kurang (underexpressed) pada rentang usia tertentu. Selain itu, beberapa penyakit komorbid prevalensinya berbeda di beberapa kelompok usia tertentu. 
Care: Jurnal Ilmiah Ilmu Kesehatan Vol .8, No.2, 2020, hal 235-245

Perbedaan angka dari hasil penelitian ini dapat disebabkan oleh banyaknya data yang tidak lengkap sehingga dilakukan eksklusi dan mempengaruhi hasil penelitian.

Pada Tabel 2, jenis kelamin pasien RSK di Poli THT-KL RSUD Dr. Soetomo Surabaya periode Februari 2018-Januari 2019 paling banyak adalah laki-laki. Dari data tersebut, diketahui jumlah pasien laki-laki jauh lebih banyak, dengan rasio laki-laki dan perempuan mencapai 1,8: 1 . Hasil penelitian ini tidak jauh berbeda pada penelitian Cho (2013) di Korea, rasio laki-laki berbanding perempuan 1,4:1. Begitu pula penelitian yang dilakukan oleh Riana (2016) di Bandung memiliki rasio laki-laki berbanding perempuan 1,27:1. Perbedaan angka dari hasil perbandingan laki-laki dan perempuan ini dapat terjadi karena jumlah sampel dan rentang waktu penelitian yang berbeda, tetapi mayoritas pada pasien RSK tetap jumlah laki-laki lebih banyak dibandingkan dengan jumlah perempuan Namun hasil penelitian ini berbeda pada penelitian di Kanada pada tahun 2013, perempuan yang paling banyak menderita RSK dengan rasio laki-laki berbanding perempuan 4:6 (Bartley, 2015). Pada penelitian Ference (2015), survey di Amerika menyatakan bahwa rasio penderita RSK pada laki-laki dan perempuan adalah 1:2. Hal ini disebabkan karena perempuan jika menderita penyakit akan sangat mempengaruhi quality of life sehingga lebih cepat mencari pertolongan ke dokter. Perbedaan hasil penelitan ini dapat disebabkan oleh perbedaan ras dan kebiasaan di wilayah Asia dan Amerika. Menurut penelitian Riana (2016), laki-laki penderita RSK lebih banyak merokok dan memiliki kombinasi faktor risiko lainnya seperti alergi, asma, dan refluks daripada perempuan, sehingga rasio penderita RSK laki-laki lebih besar daripada perempuan.

Berdasarkan Tabel 3, pasien terbanyak memiliki derajat keparahan gejala keseluruhan skala sedang, yaitu nilai VAS 4-7, sebanyak 65,11\%. Hasil penelitian ini tidak jauh berbeda dengan Lim, dkk., (2007), bahwa 46,55\% pasien memiliki derajat keparahan sedang. Pada penelitian Idugboe (2017), derajat keparahan gejala keseluruhan dengan instrument SNOT22 terbanyak adalah pasien dengan skala gejala sedang $(44,2 \%)$. Hal ini dapat terjadi karena menurut Fokkens (2012), penderita RSK yang memiliki derajat keparahan gejala $>5$ mengalami penurunan Quality of Life sehingga pasien terganggu aktivitas sehari-hari dan datang 
ke pusat pelayanan kesehatan untuk mencari pengobatan.

Pada Tabel 4 didapatkan derajat VAS obstruksi hidung terbanyak, adalah skala gejala sedang $(58,13 \%)$, derajat VAS nasal discharge terbanyak, adalah skala gejala ringan (48,86\%). Berdasarkan data penelitian, tidak ada pasien yang memiliki skala VAS 0 (nol) atau tanpa gejala. Hasil ini sesuai dengan definisi RSK menurut EPOS 2012, bahwa dua gejala utama yang dimiliki penderita RSK adalah obstruksi hidung dan nasal discharge. Dua gejala utama ini yang lebih tinggi derajat keparahannya adalah obstruksi hidung. Hal ini menurut Jackman (2006) dapat disebabkan oleh pada proses patofisiologi RSK, proses inflamasi sangat berperan besar. Selain itu mucocilliary clearance akan menurun sehingga menambah rasa hidung tersumbat. Nasal discharge yang dikeluarkan viskositas mukusnya meningkat namun produksinya berbanding terbalik dengan viskositas sehingga pasien lebih banyak mengeluhkan gejala obstruksi karena viskositas discharge yang tinggi daripada jumlah discharge banyak. Sedangkan derajat VAS nyeri wajah terbanyak adalah skala gejala ringan $(58,13 \%)$ dan derajat VAS gangguan penghidu terbanyak adalah skala gejala ringan $(62,79 \%)$. Berdasarkan hasil penelitian, pada gejala nyeri wajah dan gangguan penghidu memiliki skala VAS 0 (nol). Hal ini sesuai dengan EPOS 2012, bahwa gejala nyeri wajah dan gangguan penghidu adalah gejala penyerta yang tidak selalu ditemukan pada pasien RSK. Dari data tersebut, pasien datang ke poli dengan gejala yang paling berat adalah obstruksi hidung yaitu dengan gejala sedang. Selama ini belum ada penelitian tentang skala VAS pada derajat keparahan gejala pada pasien RSK. Menurut Damm (2002), gejala terbanyak yang mengganggu pasien hingga pasien datang ke poli adalah obstruksi hidung, diikuti dengan nasal discharge dan infeksi saluran napas. Menurut Ling (2007), hampir $84 \%$ pasien mengalami obstruksi hidung, diikuti dengan nasal discharge dan nyeri wajah.

Menurut data dalam penelitian ini, dapat dilihat di Tabel 5, pasien paling banyak memiliki faktor risiko sebanyak 27 pasien $(62,79 \%)$ dengan faktor risiko terbanyak adalah alergi sebanyak 15 pasien yang terdiri dari: 8 pasien dengan faktor risiko alergi saja, 1 pasien kombinasi alergi dan asma, 4 pasien kombinasi alergi dan refluks, dan 2 pasien kombinasi alergi, refluks, dan rokok. Faktor risiko secara berurutan menurut prevalensinya adalah alergi, merokok, refluks cairan lambung, 
dan yang paling sedikit adalah asma. Hasil penelitian ini tidak berbeda jauh dengan penelitian Riana, (2016) prevalensi faktor risiko secara berurutan yaitu alergi, merokok, dan yang paling sedikit adalah asma. Menurut Benninger (2005), sebanyak 54\% pasien RSK positif skin prick test. Menurut Stamberger (1991), penderita RSK yang memiliki alergi menyebabkan pembengkan pada mukosa hidung, diikuti dengan retensi mukus dan infeksi, dan menimbulkan gejala obstruksi hidung. EPOS 2012 menyimpulkan dari beberapa penelitian bahwa faktor risiko terbesar adalah alergi. Keterbatasan dari penelitian ini adalah cara pengambilan data menggunakan data rekam medik yang merupakan data sekunder. Peneliti tidak meninjau secara langsung kepada pasien, sehingga beberapa informasi dari pasien ada yang tidak lengkap. Selain itu, beberapa rekam medik pasien tidak ditemukan pada pusat rekam medik RSUD Dr. Soetomo sehingga jumlah pasien yang dapat diteliti berkurang.

\section{KESIMPULAN}

Berdasarkan aspek demografi didapatkan rentang usia paling banyak adalah 36-45 tahun, jenis kelamin didominasi oleh pasien laki-laki. Berdasarkan aspek klinis didapatkan derajat keparahan gejala keseluruhan dengan skala VAS paling banyak gejala sedang, gejala obstruksi hidung paling banyak skala sedang, gejala nasal discharge paling banyak skala ringan, gejala nyeri wajah paling banyak skala ringan, gejala gangguan penghidu paling banyak skala ringan. Pasien RSK paling banyak memiliki faktor risiko, dengan faktor risiko paling sering adalah alergi. Diperlukan penelitian lebih lanjut dengan menggunakan data primer dan jumlah yang lebih banyak agar memperoleh hasil yang lebih baik.

\section{UCAPAN TERIMAKASIH}

Puji syukur kepada Tuhan yang Maha Pengasih atas rahmat dan karuniaNya peneliti dapat menyelesaikan penelitian ini dengan baik. Terimakasih kepada Fakultas Kedokteran Universitas Airlangga dan RSUD Dr. Soetomo Surabaya yang telah membantu jalannya penelitian ini serta kepada Universitas Tribuwana Tunggadewi yang telah menerbitkan penelitian ini melalui Jurnal Ilmiah Ilmu Kesehatan "Care".

\section{REFERENSI}

AAO-HNS. Post Nasal Drip. 2014. American Academy of Otolaryngology Head and Neck Surgery. Alexandria, Virginia.

Arimulyani, Y. 2009. Gambaran Karakteristik Penderita Sinusitis Yang Berkunjung Ke Unit Rawat Jalan Dr. Soetomo Surabaya Pada Tahun 2009. FK Unair : Surabaya. 
[http://alumni. unair.ac.id/detail. php?id $=44646 \&$ faktas $=$ Kedokteran $]$

Bartley, J. and Wong, C., 2013. Nasal Pulmonary Interactions. Nasal Physiology and Pathophysiology of Nasal Disorders(pp. 559-566).

Benninger, M.S., Ferguson, B.J., Hadley, J.A., Hamilos, D.L., Jacobs, M., Kennedy, D.W., Lanza, D.C., Marple, B.F., Osguthorpe, J.D., Stankiewicz, J.A. and Anon, J., 2003. Adult chronic rhinosinusitis: definitions, diagnosis, epidemiology, and pathophysiology. OtolaryngologyHead and Neck Surgery, 129(3), pp.S1S32.

Cho, S.H., Hong, S.J., Han, B., Lee, S.H., Suh, L., Norton, J., Lin, D., Conley, D.B., Chandra, R., Kern, R.C. and Tan, B.K., 2012. Age-related differences in the pathogenesis of chronic rhinosinusitis. Journal of Allergy and Clinical Immunology, 129(3), pp.858-860

Damm M, Quante G, Jungehuelsing M, Stennert E. Impact of functional endoscopic sinus surgery on symptoms and quality of life in chronic rhinosinusitis. The Laryngoscope. 2002 Feb;112(2):310-5.

Depkes RI. 2003. Pola Penyakit 50 Peringkat Utama Menurut DTD Pasien Rawat Jalan di Rumah Sakit Indonesia. Profil Kesehatan Indonesia. Jakarta: Departemen Kesehatan Republik Indonesia.

Depkes RI. 2009. Profil Kesehatan Indonesia. Jakarta: Depertemen Kesehatan Republik Indonesia.

Ference, E.H., Tan, B.K., Hulse, K.E., Chandra, R.K., Smith, S.B., Kern, R.C., Conley, D.B. and Smith, S.S., 2015. Commentary on gender differences in prevalence, treatment, and quality of life of patients with chronic rhinosinusitis. Allergy \& Rhinology, 6(2), pp.ar-2015.
Fokkens, W. et al. 2012. European Position on Rhinosinusitis and Nasal Polyps. Rhinology, pp. 55-350.

Giannoni, C. M., Stewart, M. G., \& Alford, E. L. 1997. Intracranial complications of sinusitis. The Laryngoscope, 107(7), 863-867.

Idugboe, O. J., Otoghile, B., Musa, I. O., \& Adeosun, A. A. (2018). Chronic rhinosinusitis: the correlation between symptom severity score and findings on plain radiographs of the paranasal sinuses. International Journal of Otorbinolaryngology and Head and Neck Surgery, 4(1), 5.

Jackman, A.H. and Kennedy, D.W., 2005. Pathophysiology of sinusitis. Infectious Disease And Therapy Series, 35, p.109.

Lim M, Lew-Gor S, Darby Y, Brookes N, Scadding G, Lund VJ. 2007. The relationship between subjective assessment instruments in chronic rhinosinusitis. Rhinology. Jun;45(2):144-7.

Ling FT, Kountakis SE. Important clinical symptoms in patients undergoing functional endoscopic sinus surgery for chronic rhinosinusitis. The Laryngoscope. 2007 Jun;117(6):1090-3.

Lund, V. J. 2007. Impact of chronic rhinosinusitis on quality of life and health care expenditure. Hamilos DL, Baroody FM, eds. Chronis rbinosinusitis pathogenesis and medical management. New York: Informa. Hal : 15-21.

Mahdavinia, M. and Grammer III, L.C., 2013. Chronic rhinosinusitis and age: is the pathogenesis different?. Expert review of anti-infective therapy, 11(10), pp.1029-1040.

Rahmawati, A.Q.P. and Savitri, E., 2008. Relationship between rhinitis severity, skin prick test reactivity and mite-specific immunoglobulin $\mathrm{E}$ in allergic rhinitis patients in Makassar. Indonesian J Med Sci, 1, pp.1-9.

Riana, D., Dermawan, A., Wijana, W. and Saifuddin, O.M., 2016. 
Care: Jurnal Ilmiah Ilmu Kesehatan Vol .8, No.2, 2020, hal 235-245

Chronic Rhinosinusitis Patient with Nasal Polyp Characteristics at Otorhinolaryngology-Head and Neck Surgery Outpatient Clinic, Dr. Hasan Sadikin General Hospital, Bandung. International Journal of Integrated Health Sciences, 4(2), pp.6266.

Stammberger, H., 1991. Functional endoscopic nasal and paranasal sinus surgery. The Messerklinger technique. Toronto-Philadelphia: BC Decker.

US Census Bureau. International Data Base. 2004. Chronic Sinusitis in Asia. Diakses $20 \quad$ Maret 2018. http://www.cureresearch.com/c/ch ronic sinusitis/stats-

country printer.htm.] 